camphonanic acid is similar to the formation of trans-hydroxydihydroaminocampholytic acid from the cis-dihydroaminocampholytic acid.

The investigation will be continued.

URBANA, ILL.

\title{
AN EFFICIENT APPARATUS FOR FRACTIONAL DISTILLATION UNDER DIMINISHED PRESSURE.
}

By William A. Noyes and GlenN S. Skinner.

Received September 4, 1317.

As indicated in the preceding article we have devised a simple apparatus for the fractionation of the methyl esters formed in the decomposition of

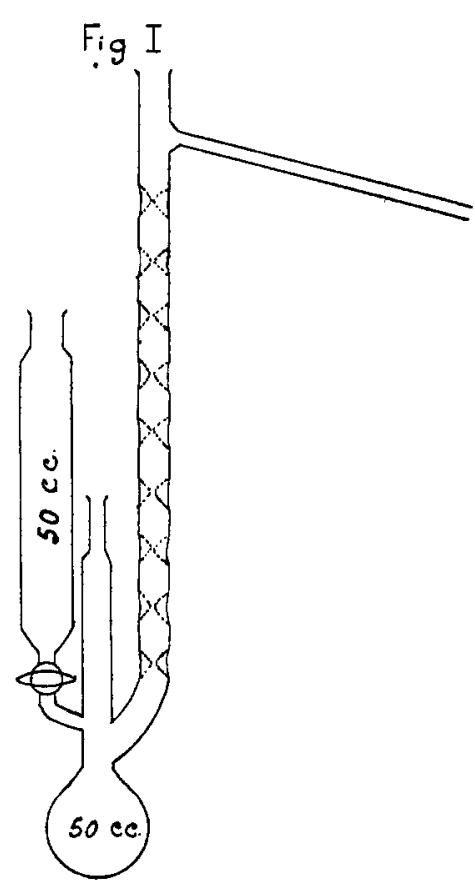
methyl isoaminocamphonanate with nitrous acid. We have found the apparatus so convenient and effective that it seems worth while to describe it.

It may be easily made from apparatus ordinarily found in the chemical laboratory, the essential parts being a separatory funnel, a Claissen bulb and a fractionating column. The apparatus, as may be seen from the diagram, offers the advantages: (I) that it may be used advantageously with either small or large fractions of material by regulating the flow of the entrant fraction from the funnel, and (2) that the successive fractions may be introduced without losing the vacuum. In case bulbs are used as receivers a wide mouth stopcock may be introduced into the side tube to serve the second purpose. The fractionating column may be made from tubing of convenient size by softening the glass at the proper points in the small flame of a blast lamp and indenting with the point of an iron wire. ${ }^{1}$ The points thus made should almost touch, and each successive pair of indentations should be at right angles to the preceding. The column used in our apparatus had 34 pairs of indentations in a length of $25 \mathrm{~cm}$.

In order to give some idea of the efficiency of the apparatus a portion of the data for one fractional distillation is given in Table I.

1 This form of a fractionating tube was first seen by one of us in the laboratory of Sir William Ramsay. 
TABLE I.

Boiling point. Temperature of bath.

A. ${ }^{1}$

Pressure. Weight.

$90-95^{\circ}$
$95^{-100^{\circ}}$
$100-108^{\circ}$
$108-120^{\circ}$
$120-130^{\circ}$
$130-142^{\circ}$

$110-120^{\circ}$

$20 \mathrm{~mm}$.

$50 \mathrm{~g}$.

20

29

I30

20

18

2016

$140-145^{\circ}$

20

22

160

20-2I

$53 / 188 \mathrm{~g}$

$83-88^{\circ}$

$120-130^{\circ}$

B. ${ }^{2}$

$85^{-} 92^{\circ}$

$86-95^{\circ}$

$90-105^{\circ}$

$105-120^{\circ}$

$120-130^{\circ}$

$120-135^{\circ}$

135

$145-160^{\circ}$

$120-127^{\circ}$

$150-165^{\circ}$

$127^{-135^{\circ}}$

$180-190^{\circ}$

$135-142^{\circ}$

$180-220^{\circ}$

$20 \mathrm{~mm}$.

35

20

$3 \mathbf{I}$

20

2 I

20

12

$2 I$

22

$21 \quad 33$

2 I 29

$-86^{\circ}$

$86-90^{\circ}$

120

c.

$88-93^{\circ}$

$120-130^{\circ}$

II $5-145^{\circ}$

$140-150^{\circ}$

$140-150^{\circ}$

$2 I$

35

93-11 $0^{\circ}$

$110-120^{\circ}$

$140-150^{\circ}$

$120-125^{\circ}$

$125^{-135^{\circ}}$

I 60

$133^{-137^{\circ}}$

160

$2 I$

35

$2 I$

34

2 I

22

229

$22 \quad 23$

$21 \quad 32$

$2 I .22$

I $37-139^{\circ}$

$165^{-1} 70^{\circ}$

20

19

$20 \quad 22 / 218$

$79^{-} 83^{\circ}$

II 5

D.

$79-83^{\circ}$

105

$80-86^{\circ}$

$110-115^{\circ}$

$120-140^{\circ}$

$140-145^{\circ}$

$140-150^{\circ}$

150

$165^{-1} 75^{\circ}$

$165^{-1} 75^{\circ}$

E.

I5 37

I5 34

I5 17

158

$15 \quad 32$

$112-120^{\circ}$

$120-126^{\circ}$

$126-134^{\circ}$

$134-136^{\circ}$

$105-110^{\circ}$

$8 \mathrm{I}-8 \mathrm{r} \cdot 5^{\circ}$

105-110

$125-\times 35^{\circ}$

$84-105^{\circ}$

$105-112^{\circ}$

$112-115^{\circ}$

$115-122^{\circ}$

$145-150^{\circ}$

160

$122-135^{\circ}$

$134^{-1} 35^{\circ}$

160

$160-170^{\circ}$

$15 \quad 25$

154

.15

I5 $44 / 214$

$16 \quad 39$

$16 \quad 3^{8}$

I6 II

1620

$16 \quad 32$

16216

1616

I6 46/223

1 Without fractionating apparatus. The products were distilled into about $30 \mathrm{~g}$. of intermediate fractions from previous decompositions at the proper times.

${ }^{2}$ With fractionating apparatus. The fractions were weighed with no greater accuracy than I g., and the residues were not taken uniformly into account. This accounts for the non-agreement of the weight totals. 


\begin{tabular}{|c|c|c|c|}
\hline \multirow[b]{2}{*}{ Boiling point. } & \multicolumn{2}{|c|}{ TABLE I (continued). } & \multirow[b]{2}{*}{ Weight } \\
\hline & $\begin{array}{r}\text { Temperature of bath. } \\
\text { F. }\end{array}$ & Pressure & \\
\hline $78.5-79^{\circ}$ & $100-105^{\circ}$ & 15 & 50 \\
\hline $79^{-85^{\circ}}$ & $105^{-110^{\circ}}$ & 15 & 28 \\
\hline $85^{-108^{\circ}}$ & $125^{-1} 45^{\circ}$ & 15 & 8 \\
\hline $108-\operatorname{II} 2^{\circ}$ & I 40 & 15 & 5 \\
\hline $\mathrm{IIO}_{\mathrm{III}} 4^{\circ}$ & $140-145^{\circ}$ & 15 & 38 \\
\hline I $12-$ I $20^{\circ}$ & $145^{-1} 50^{\circ}$ & I 5 & 8 \\
\hline
\end{tabular}

[CONTRIBUtion From the Henry Phipps Institute of the University of Pennsyluania.]

\section{DICHLOROAMINE T. AND CHLORINATED EUCALYPTOL I.2.}

By Robert B. Krauss and Edward Crede.

Received October 19, 1917.

Since the introduction of Dichloroamine T. (Toluene- $p$-sulfondichloroamide) for the treatment of infected wounds by Dakin, Lee, Sweet, Hendricks and LeConte, ${ }^{1}$ the production of this substance in pure form and on a large scale, as well as that of suitable solvents for its application, have become problems of importance. As originally used for this purpose, Dichloroamine $T$. was dissolved in a prepared etucalyptol (chlorinated) and used in this condition or further diluted with Prepared Paraffin Oil (chlorinated).

It was early recognized by the authors that the products obtained by the action of chlorine on eucalyptol may vary considerably according to the conditions of chlorination. By continued chlorination alone several preparations can be obtained, particularly chlorinated eucalyptol, specific gravity I.2, which are at present the subject of extended study by surgeons.

The present paper is intended to describe briefly an improved method for the large scale production of Dichloroamine $T$., the preparation of Chlorinated Eucalyptol I.2, as well as other results of the chlorination of eucalyptol.

Method for Large Production of Dichloroamine T.--Toluene- $p$-sulfonamide is dissolved in ten parts of $\mathbf{I}:$ Io caustic soda $\left(39^{\circ}\right.$ Bé.) and diluted with twenty parts of water. The solution is carefully filtered to remove ferric hydroxide. Chlorine from a cylinder is then passed into the solution until a voluminous white precipitate of toluene-p-sulfondichloroamide is formed. This, collected on a filter, throughly washed twice with $5^{-8}$ parts of water and finally with enough Io $\%$ alcohol to make a thin paste. The dilute alcohol washing should be done very quickly and the substance separated with the aid of a vacuum filter. It is then dried at a temperature not exceeding $55^{\circ}$, preferably in a vacuum dryer.

$$
1 \text { J.Am. Med. Assoc., 69, } 27 \text { (1917). }
$$

